\title{
The Role of Endoscopic Ultrasound in Pancreatic Cancer Staging in the Era of Neoadjuvant Therapy and Personalised Medicine
}

\author{
Miguel Bispo ${ }^{a}$ Susana Marques ${ }^{a}$ Ricardo Rio-Tinto ${ }^{a}$ Paulo Fidalgo $^{a}$ \\ Jacques Devière ${ }^{a, b}$ \\ a Department of Gastroenterology and Digestive Endoscopy, Champalimaud Foundation, Lisbon, Portugal; \\ ${ }^{b}$ Department of Gastroenterology, Hepatopancreatology, and Digestive Oncology, Erasmus University \\ Hospital - Université Libre de Bruxelles, Brussels, Belgium
}

\section{Keywords}

Endoscopic ultrasound · Fine-needle biopsy · Neoadjuvant therapy · Pancreatic cancer staging · Personalised medicine . Precision therapy

\section{Abstract}

Precise staging of pancreatic cancer is crucial for treatment choice. In clinical practice, this includes the TNM staging and determination of tumour resectability, based on a multimodality imaging workup. International guidelines recommend multi-detector computed tomography (CT), with a dedicated pancreatic protocol, as the first-line tool for TNM staging and evaluation of tumour-vessel relationships. In non-metastatic disease upon initial CT assessment, both magnetic resonance imaging and endoscopic ultrasound (EUS) may add relevant information, potentially changing treatment sequence. EUS may have distinct advantages in pancreatic cancer diagnosis and staging when compared with other modalities, being particularly valuable in the determination of portal venous confluence involvement (particularly in small and ill-defined/isoattenuating tumours on CT), in locoregional nodal staging and in the detection of ascites. As we step forward to a more frequent use of neoadjuvant chemotherapy and to personalised medicine, the importance of EUS-guided fine-needle biopsy (EUS-FNB) also increases. The recent availability of third-generation biopsy needles significantly increased the diagnostic yield of EUS-guided tissue acquisition, providing diagnostic cell blocks in approximately $95 \%$ of cases with only two dedicated passes and allowing ancillary testing, such as immunohistochemistry and molecular profiling of the tumour. In this article, the authors present an updated perspective of the place of EUS and EUS-FNB in the staging algorithm of pancreatic cancer. Data supporting the increasing role of neoadjuvant therapy and the importance of a patient-tailored treatment selection, based on tumoural subtyping and molecular profiling, are also discussed.

C 2020 Sociedade Portuguesa de Gastrenterologia Published by S. Karger AG, Basel

\section{O papel da ecoendoscopia no estadiamento do cancro do pâncreas na era da terapêutica neoadjuvante e da medicina personalizada}

\section{Palavras Chave \\ Ecoendoscopia $\cdot$ Biopsia por agulha fina $\cdot$ Estadiamento do cancro do pâncreas - Medicina personalizada . Terapêutica neoadjuvante · Terapêutica de precisão}

\section{Resumo}

No cancro do pâncreas é fundamental um estadiamento preciso para a decisão terapêutica. Na prática clínica, isto karger@karger.com www.karger.com/pjg

Karger $\stackrel{\text { ' }}{5}$

BOPEN ACCESS
(C) 2020 Sociedade Portuguesa de Gastrenterologia Published by S. Karger AG, Basel

This article is licensed under the Creative Commons AttributionNonCommercial-NoDerivatives 4.0 International License (CC BY NC-ND) (http://www.karger.com/Services/OpenAccessLicense). Usage and distribution for commercial purposes as well as any distribution of modified material requires written permission.
Department of Gastroenterology and Digestive Endoscopy

Champalimaud Foundation, Av. Brasília

PT-1400-038 Lisbon (Portugal)

miguel.bispo@fundacaochampalimaud.pt 
inclui o estadiamento TNM e a avaliação da ressecabilidade cirúrgica, baseada numa avaliação imagiológica multimodal. As recomendações de consenso recomendam a tomografia computorizada (TC) multi-detector, com protocolo pancreático, como exame de primeira linha para o estadiamento TNM e determinação de invasão vascular loco-regional. Na doença loco-regional não-metastática (após TC inicial), a ressonância magnética e a ecoendoscopia poderão acrescentar informação relevante, com potencial impacto na decisão terapêutica. A ecoendoscopia apresenta vantagens únicas comparativamente a outros métodos de estadiamento, sendo particularmente útil na avaliação da relação do tumor com a confluência espleno-portal (especialmente na presença de tumores pequenos e isodensos/mal-definidos na TC), no estadiamento ganglionar loco-regional $(\mathrm{N})$ e na detecção de ascite. À medida que caminhamos no sentido da utilização crescente de quimioterapia neoadjuvante e da Medicina personalizada, a relevância da biopsia guiada por ecoendoscopia também aumenta. A recente disponibilização de agulhas de biopsia de terceira geração aumentou significativamente a rentabilidade diagnóstica da punção guiada por ecoendoscopia, obtendo cellblocks para avaliação histológica em cerca de $95 \%$ dos casos (com apenas duas passagens), permitindo a realização de estudos ancilares, como avaliação imuno-histoquímica e caracterização molecular do tumor. No presente artigo os autores apresentam uma perspetiva do papel atual da ecoendoscopia e da biopsia guiada por ecoendoscopia no algoritmo de estadiamento do cancro do pâncreas. É ainda analisada a evidência atual que favorece o papel crescente da terapêutica neoadjuvante e a importância da seleção individualizada do tratamento, baseada na definição do subtipo de tumor e na caracterização molecular.

(c) 2020 Sociedade Portuguesa de Gastrenterologia Publicado por S. Karger AG, Basel

\section{Introduction}

Endoscopic ultrasound (EUS) has become an important adjunct modality for the diagnosis, staging and therapeutic decision in pancreatic cancer $[1,2]$. In large metaanalyses and in comparative studies with other imaging modalities, EUS was found to be the most accurate tool for the detection of small pancreatic masses $(\leq 2 \mathrm{~cm})$, with a pooled sensitivity of over $95 \%[2,3]$.

Tissue acquisition for pathological documentation of pancreatic cancer is mandatory before chemotherapy [4, 5], and increasingly more patients receive such chemo- therapy before having a surgical specimen available [6]. Indeed, neoadjuvant therapy is becoming a standard practice for borderline resectable tumours, offering a better chance of achieving a complete surgical resection (R0) [7] and a longer survival after resection [8]. The recent availability of the so-called third-generation fine-needle biopsy (FNB) needles increased significantly the diagnostic yield of EUS-guided tissue acquisition of pancreatic masses [9, 10]. These new FNB needles with cutting edges (crown-tip and fork-tip) are rapidly replacing fine-needle aspiration (FNA) needles in clinical practice given their ability to acquire diagnostic cell blocks in approximately $95 \%$ of cases with only two dedicated passes, obviating the need for rapid onsite evaluation $[9,11]$. Histological samples can be reliably acquired with these new needles, allowing to perform ancillary testing, such as immunohistochemistry and molecular profiling of the tumour [9-11]. In the era of neoadjuvant chemotherapy and personalised cancer Medicine, EUS-FNB has therefore become a powerful tool in the management of pancreatic cancer [1]. On the one hand, it is an important adjunct to multi-detector computed tomography (CT) and magnetic resonance imaging (MRI) in the multimodality staging of pancreatic cancer and, on the other hand, it allows a safe and effective core tissue acquisition for histology, assessment of tumour markers and tumour gene profiling [1,9-11].

In this article, the authors present an updated perspective of the place of EUS-FNB in the staging algorithm of pancreatic cancer. Data supporting the increasing role of neoadjuvant therapy for non-metastatic pancreatic cancer and the growing importance of a patient-tailored treatment selection based on tumour subtyping and genetic profiling are also discussed.

A literature search was performed until March 2020, using PubMed Central, Scopus and Google, using the key words and phrases: "pancreatic cancer/adenocarcinoma staging," "endoscopic ultrasound," "fine-needle biopsy," "neoadjuvant chemotherapy," "personalized cancer Medicine" and "precision therapy." Prospective/comparative studies, meta-analyses and international consensus guidelines were preferred.

\section{Anatomic Staging, Clinical Staging and Therapeutic Decision by Stage}

Pancreatic cancer staging includes:

1. The classification of the tumour stage, using preferably the 8th edition of the American Joint Committee on Cancer (AJCC) classification (2017) (Table 1) [12]. 
Table 1. The TNM staging system (7th and 8th editions) from the American Joint Committee on Cancer (AJCC)

\begin{tabular}{lll}
\hline Stages & Seventh Edition (2010) & Eight Edition (2017) \\
\hline T1 & Tumour limited to the pancreas, $\leq 2 \mathrm{~cm}$ in greatest dimension & Maximum tumour diameter $\leq 2 \mathrm{~cm}$ \\
\hline T2 & Tumour limited to the pancreas, $>2 \mathrm{~cm}$ in greatest dimension & Maximum tumour diameter $2-4 \mathrm{~cm}$ \\
\hline T3 & $\begin{array}{l}\text { Tumour extends beyond the pancreas but without involvement of the } \\
\text { celiac axis or the superior mesenteric artery }\end{array}$ & Maximum tumour diameter $>4 \mathrm{~cm}$ \\
\hline T4 & $\begin{array}{l}\text { Tumour involves the celiac axis, superior mesenteric artery or common } \\
\text { hepatic artery (unresectable primary tumour) }\end{array}$ & $\begin{array}{l}\text { Tumour involves the celiac axis, superior } \\
\text { mesenteric artery or common hepatic artery }\end{array}$ \\
\hline N0 & No regional lymph node metastasis & No regional lymph node metastasis \\
\hline N1 & Regional lymph node metastasis & Metastasis in $1-3$ regional lymph nodes \\
\hline N2 & Non-existent & Metastasis in $\geq 4$ regional lymph nodes \\
\hline
\end{tabular}

In the 8th edition, the T stage is nearly entirely based on the tumour size and, although T4 is still defined by celiac trunk, superior mesenteric artery or common hepatic artery involvement, it is no longer categorized as unresectable disease. Also, the $\mathrm{N}$ stage is stratified into N1 and N2 (according to the number of involved regional lymph nodes) [12].

The primary goal of the revised AJCC criteria is providing information on prognosis, rather than guiding patient management [12].

2. The precise description of the relationship between the tumour and the portal vein/portal venous confluence, superior mesenteric vein, superior mesenteric artery, celiac trunk and common hepatic artery [4]. An imaging staging reporting template should preferably be used to ensure complete assessment of all imaging criteria essential for optimal staging, which will improve the decision-making process [13].

3. The determination of the clinical stage and the resectability status (based on the integration of the imaging test results and eventual staging laparoscopy), which impacts on therapeutic decision-making, considering 4 stages [4]:

(a) Metastatic disease, which generally benefits from palliative chemotherapy.

(b) Locally advanced disease, also with indication for chemotherapy, due to local vascular spread that precludes complete resection. However, about one-third of these patients may have significant tumour shrinkage with chemotherapy allowing secondary resection of the primary tumour [14]. Hence, in the 8th edition of the AJCC classification, the T4 stage is no longer classified as unresectable [12].

(c) Borderline resectable disease, with indication for neoadjuvant chemotherapy, usually followed by resection surgery.

(d) Resectable disease, usually treated with primary resection surgery, although neoadjuvant chemotherapy with secondary surgery is increasingly being performed in this stage $[4,5]$.

The classification system for resectability based on tumour-vessel relationships (which categorises the tumour in resectable, borderline resectable and unresectable) correlates with the likelihood of achieving a $\mathrm{R} 0$ resection and the most widely accepted criteria are from the National Comprehensive Cancer Network (NCCN) [4]. The anatomic definition for borderline resectable cancer, which often requires vascular reconstructions for resection and carries a high risk of positive margins, justifying preoperative chemotherapy, is variable across different classifications systems. The recent guidelines of the American Society of Clinical Oncology (ASCO) categorise as "borderline resectable" any tumour-vascular contact (of any degree), recommending neoadjuvant therapy instead of primary resection $[15,16]$. It must be highlighted that the anatomic criteria for resectability (determined by imaging findings alone) are clearly insufficient, as a significant proportion of patients with tumours classified as primary resectable ultimately have positive margins and residual disease following resection [17]. Therefore, additional criteria were added in the decision for neoadjuvant chemotherapy (instead of primary surgery) for potentially resectable disease, including biological factors (CA19.9 > $500 \mathrm{IU} / \mathrm{mL}$ and suspicion of regional lymph node metastases) and clinical criteria (as the presence of persistent "pancreatic pain," significant weight loss and poor general condition, with ECOG performance status $\geq 2$ ) [4, 17]. 
The Era of Neoadjuvant Chemotherapy and Personalised Medicine

All imaging modalities tend to understage pancreatic cancer and even patients with $\mathrm{R} 0$ resection have poor outcomes, with nearly half of them experiencing tumour recurrence in the first postoperative year [18]. Guidelines endorsed by the European Society for Medical Oncology (ESMO) indicate that only patients with a high probability of complete $(\mathrm{R} 0)$ resection should receive upfront surgery [19]. The recent expansion of the indications for neoadjuvant chemotherapy is the result not only from a new perspective of "borderline resectable cancer" (integrating clinical criteria and data related to biological behaviour of the tumour) $[4,17]$, but also from emerging data of phase III trials (PREOPANC-1 e Prep-02/JSAP05), pointing out to a potential benefit of neoadjuvant therapy even in resectable disease $[7,20]$. The Dutch PREOPANC-1 trial, which included patients with resectable and borderline resectable disease, showed a significant increase in the $\mathrm{R} 0$ resection rate, longer disease-free survival and lower rates of metastatic lymph nodes in patients who underwent neoadjuvant therapy when comparing with those receiving upfront surgery ( $\mathrm{R} 0$ resection rate was $40 \%$ after upfront resection versus $71 \%$ after neoadjuvant therapy) [7]. Another recent prospective randomised trial of patients with borderline resectable disease was closed prematurely when an interim analysis found a superior median overall survival of 21 months for neoadjuvant therapy versus 12 months for upfront surgery [8]. Neither of the previously mentioned trials $[7,8]$ evaluated the impact of neoadjuvant therapy with FOLFIRINOX, a more effective regimen than gemcitabine alone in the metastatic setting [6]. In three ongoing trials evaluating neoadjuvant FOLFIRINOX in patients with resectable pancreatic cancer [21-23], it is expectable that even better results regarding the overall survival will be achieved in the neoadjuvant FOLFIRINOX group [6].

Neoadjuvant chemotherapy has several advantages: (1) improved local tumour control, increasing the likelihood of negative-margin (R0) resections; (2) identification of patients with rapidly progressive disease, who can then be spared from the morbidity associated with a potentially useless surgery; and (3) optimisation of the access to chemotherapy, taking into account that after a major pancreatic resection surgery, up to $40 \%$ of patients are too ill to receive adjuvant chemotherapy $[18,24]$. Therefore, there is growing evidence favouring preoperative chemotherapy also in potentially resectable disease, with some authors advocating its use in all cases of pancreatic cancer, with the exception of T1N0-stage (stage Ia: tumour limited to the pancreas $\leq 2 \mathrm{~cm}$ ) [25].

The 2020 NCCN guidelines recommend tumour gene profiling for patients with locally advanced or metastatic disease who are candidates for anti-cancer therapy to identify potentially targetable mutations [4]. The NCCN advocates that testing for actionable somatic findings should be considered prior to chemotherapy in these patients, specifically including, but not limited to: fusions (ALK, NRG1, NTRK, ROS1), mutations (BRAF, BRCA1/2, HER2, KRAS, PALB2), and mismatch repair deficiency [4]. Pathological confirmation of the diagnosis of pancreatic ductal adenocarcinoma is mandatory before chemotherapy, and the NCCN recommends obtaining a core biopsy, if possible, to acquire adequate tissue for ancillary studies (immunohistochemistry and molecular profiling) [4].

Pancreatic cancer diagnosis must be precise and, preferably, should be confirmed preoperatively by EUS-guided tissue sampling, as, in reference centres, nearly $7 \%$ of patients undergoing pancreatoduodenectomy for suspected malignancy ultimately have a benign disease [26]. As we step forward to a more frequent use of neoadjuvant chemotherapy and to personalised cancer treatment, the importance of EUS-guided core biopsy also increases.

Whole genome sequencing of pancreatic cancer has shown frequent chromosomal rearrangements leading to gene disruption, affecting genes known to be important in pancreatic cancer development as new candidate drivers of pancreatic carcinogenesis [27]. Over the last decade, multiple study groups have characterised the complex molecular landscape of pancreatic cancer and have described distinct disease subtypes [28]. Five subtypes of pancreatic cancer have recently been defined analysing gene expression features from both tumour and stromal compartments, which were shown to have distinct biology and prognostic implications [29].

The majority of pancreatic cancer patients are still treated with standard (non-target) combination chemotherapy regimens [30]. The difficulty in identifying targets for anti-cancer therapy in pancreatic cancer has been mostly related to three relevant issues: (1) pancreatic cancer has long been thought to be a monomorphic disease, largely defined by 4 non-targetable genomic alterations (in KRAS, TP53, CDKN2A, and SMAD4), with a high heterogeneity of additional mutations, present at low-level frequencies [30, 31]; (2) the difficulty in obtaining adequate tumour samples as a source of genomic material for molecular studies [30-32]; (3) the technological demands and prolonged period of time to receive results 
from molecular studies, precluding a timely result for clinical application [28]. However, emerging data from translational research and recent technological developments in tumour tissue acquisition and in next-generation sequencing technology support the need of "bringing pancreas cancer into the lab" [30]. Aguirre et al. [33] have recently demonstrated a surprisingly high rate of potentially clinically actionable findings in metastatic pancreatic cancer, including a high rate of druggable oncogene lesions in cases harbouring wild-type KRAS genes. In the COMPASS trial, Aung et al. [34] found potentially targetable genomic alterations in 30\% of patients with advanced pancreatic cancer and demonstrated that prospective whole genome sequencing and RNA sequencing can be feasible within an adequate time range for clinical application. Very recently, Singhi et al. [31] found in a large cohort of pancreatic cancer patients (both in formalin-fixed biopsies and surgical resection specimens) targetable genomic alterations in $17 \%$ of the cases.

The difficulty in obtaining adequate tumour samples for genomic sequencing has also been for many years an important drawback for molecular profiling of pancreatic cancer, having been traditionally performed on resected primary tumours and, more recently, on imageguided percutaneous core biopsies from metastatic disease $[31,33,34]$. Pancreatic cancer is comprised of a high-density stroma, and the specimens obtained by EUS-FNA are often considered insufficient, contaminated, composed of poor-quality DNA/RNA and suboptimal for genetic analysis [32]. Recent advances in EUSguided tissue acquisition, with the availability of thirdgeneration FNB needles, significantly increased the diagnostic yield of EUS-guided sampling of pancreatic masses, providing true histological core tissue with a 20fold higher area when compared to standard FNA needles [35]. This new generation of cutting needles acquire diagnostic cell blocks in approximately $95 \%$ of cases with only two dedicated passes, allowing to perform ancillary testing of the tumour [9-11, 35]. With EUS-FNB, an important step was taken towards precision therapy in pancreatic cancer, with emerging data showing that EUSFNB may acquire sufficient tissue for tumour molecular profiling using next-generation sequencing in more than $90 \%$ of the tumours [32]. Tumour molecular profiling may offer a method of identifying potentially targetable genomic alterations, but currently it will only benefit a small proportion of patients [29]. Therefore, direct assessment of prediction of chemotherapy response, using tumour models such as organoids or xenograft models, can be an additional way of tailoring therapy for each pa-

Endoscopic Ultrasound In Pancreatic Cancer Staging tient [36]. Lacomb et al. [37] have recently shown that successful organoid creation was feasible in $84 \%$ of EUSFNB samples from pancreatic cancer patients. Recently, Tiriac et al. [36] performed drug sensitivity profiling of pancreatic cancer in organoid models and elucidated novel functional subtypes that predict chemotherapy sensitivity. Identification of molecular and functional subtypes of pancreatic cancer to predict chemotherapy response is urgently needed to improve treatment outcomes in pancreatic cancer. Given the aggressive behaviour of pancreatic cancer, molecular profiling should be done early in the disease course to guide precise treatment decisions [28]. Molecular profiling and subtyping classification of pancreatic cancer will undoubtedly be the future of pancreatic cancer management, but already holds great meaning in the present, being recommended for patients with advanced disease in the 2020 NCCN guidelines [4].

\section{The Place of EUS in the Staging Algorithm}

Several international guidelines on the diagnosis and management of pancreatic cancer (NCCN 2020 [4], NICE 2018 [38], ACR 2017 [39], ASCO 2016 and 2017 [15, 16] and ESMO 2015 [19]) recommend multi-detector CT, with a dedicated pancreatic protocol (dual-phase, thinsection image acquisition, followed by multiplanar reformation) as the first-line tool for diagnosis and tumour staging. No other imaging study is required in metastatic pancreatic cancer. Multi-detector CT is recommended as the modality of choice for evaluation of tumour-vessel relationships, being particularly accurate for assessing tumour involvement of the local arterial vasculature $[4,15$, $19,38,39]$. However, four important limitations of CT for initial staging must be pointed out: (1) the evaluation of isoattenuating tumours (when tumour attenuation is identical to the normal pancreatic parenchyma), corresponding to $5-17 \%$ of all pancreatic tumours; (2) the poor overall performance in detecting and characterising local lymph nodes (with sensitivity values below $30 \%$ for regional nodal metastases, independent of the morphological criteria being used); (3) inadequate sensitivity for detecting small $(\leq 10 \mathrm{~mm})$ liver metastases (sensitivity of only $69 \%$, significantly lower comparing to MRI); (4) the assessment of peritoneal carcinomatosis, given the frequent small size and possible miliary distribution of peritoneal metastases $[15,18]$.

As a result, in non-metastatic pancreatic cancer after initial CT assessment, both MRI and EUS can potentially add 
Fig. 1. Linear-array EUS. a Hypoechoic mass of the pancreatic head with loss of the hyperechoic interface between the pancreatic parenchyma and the wall of the portal vein. b Hypoechoic mass of the pancreatic body with loss of the hyperechoic interface between the parenchyma and the wall of the splenic artery (AE).
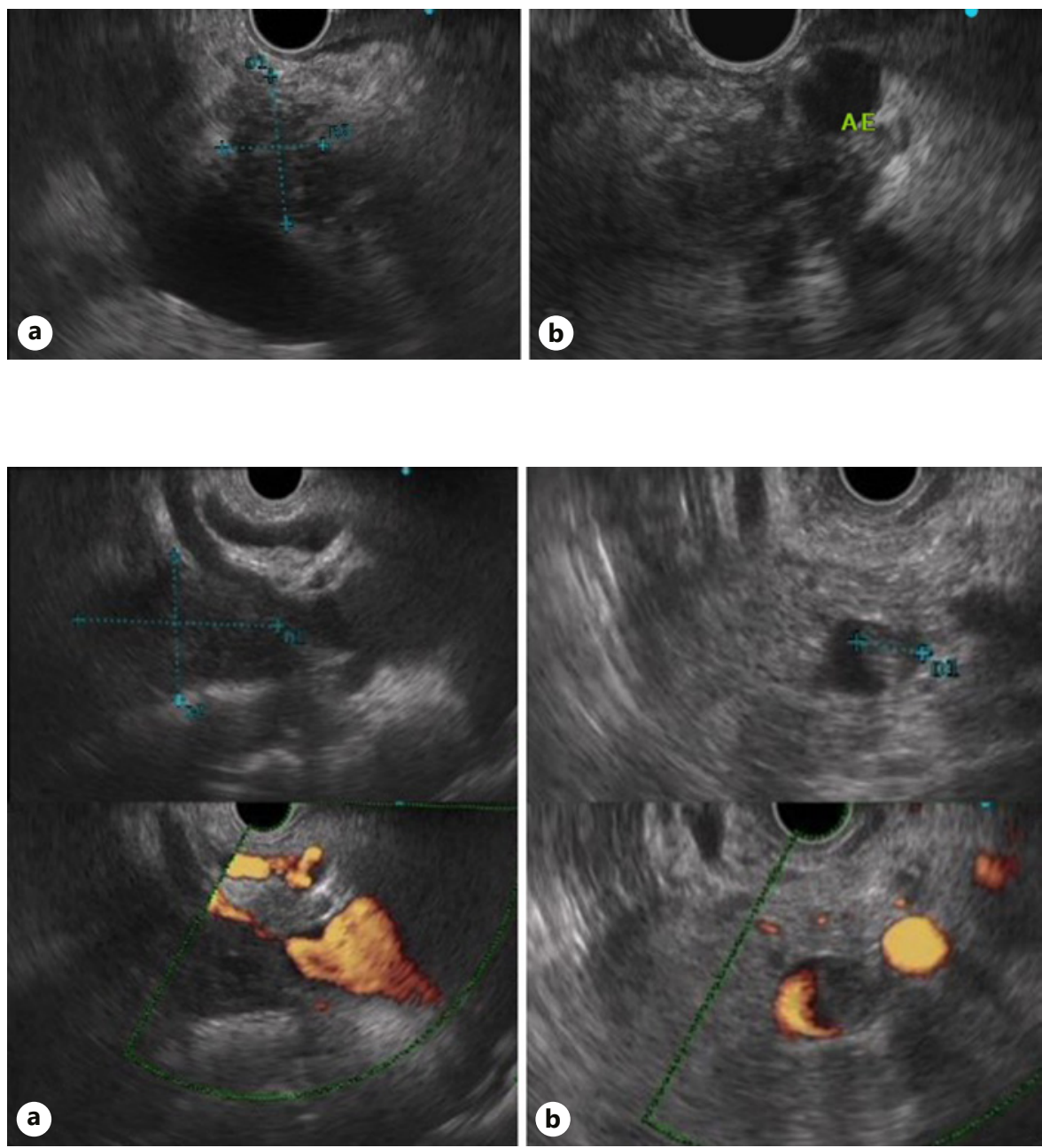

b
Fig. 2. Linear-array EUS. a Hypoechoic mass of the pancreatic head causing luminal narrowing and irregularity of the wall of the portal venous confluence (upper figure: B-mode imaging; lower figure: power Doppler imaging). $\mathbf{b}$ Isoechoic mass of the pancreatic body with encasement of the splenic vein and a mass within the vessel lumen (upper figure: B-mode imaging; lower figure: power Doppler imaging).

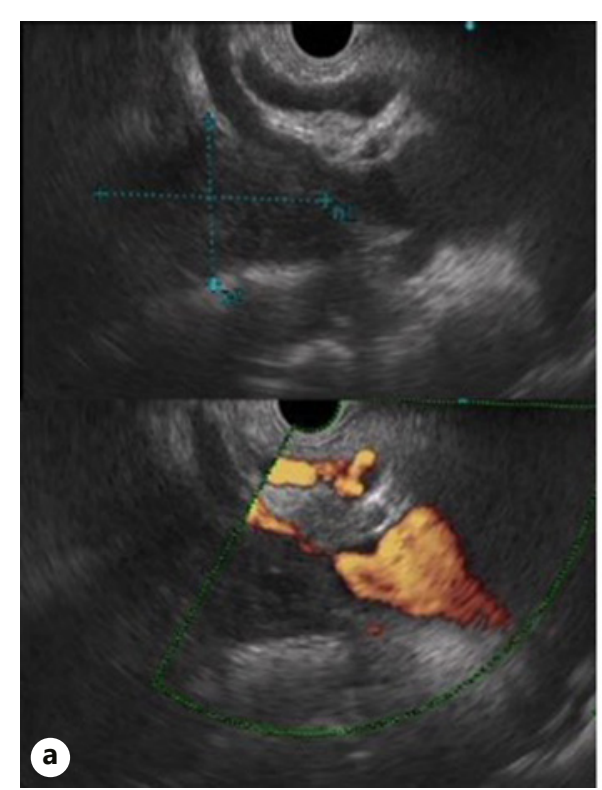

patients), which evaluated the potential benefit of EUS for identifying borderline/unresectable disease after initial pancreatic protocol CT, found that EUS results might change patient management from upfront surgery to chemotherapy in $14 \%$ of cases [42].

A meta-analysis including 29 studies and 1,330 patients pointed out to a similar performance between EUS and CT scan for evaluating tumour vascular invasion and predicting resectability [41]. However, several studies suggested that EUS may be more sensitive than CT in assessing venous invasion (in particular portal vein/venous confluence involvement), whereas CT scan is considered more sensitive in detecting arterial invasion (of the celiac trunk, superior mesenteric artery and common hepatic artery) $[41,44,45]$. There are four EUS criteria to predict tumour vascular invasion: (1) loss of the vessel-parenchymal hyperechoic interface (Fig. 1); (2) vessel wall irregularity or luminal narrowing (Fig. 2a); (3) tumour within 
the vessel lumen (Fig. 2b); (4) peri-pancreatic venous collaterals in an area of a mass that obliterates the normal anatomic location of a vessel $[1,43]$.

Pancreatic cancer is characterised by early lymph node spread, and nodal metastases are present in the majority of patients who undergo surgery, even in the absence of morphological criteria for malignant lymphadenopathies assessed by different imaging modalities $[39,46]$. In a recent meta-analysis evaluating the clinicopathological features of pancreatic cancer according to tumour size (in surgical specimens), lymph node metastases were documented in $79.1 \%$ of tumours $>2 \mathrm{~cm}$ and $64.2 \%$ of tumours $\leq 2 \mathrm{~cm}$ [46]. All imaging modalities tend to underestimate nodal metastases, and EUS (with or without FNB) is currently the most accurate modality to determine the $\mathrm{N}$ stage, with a pooled sensitivity of $69 \%$ (vs. sensitivity values below 30\% for CT and MRI) [1, 18, 41]. Specificity values for detecting lymph node metastases are similar between EUS, CT and MRI (81-88\%) [1, 18, 41]. At present, identification of regional lymph nodes suspicious of metastasis (more accurately determined by EUS than by CT or MRI, without necessarily being confirmed by FNB) has a significant clinical impact, as these patients will benefit from neoadjuvant therapy [17].

Response evaluation to neoadjuvant therapy (restaging) is challenging. All imaging studies tend to underestimate the response to chemotherapy, and the diagnostic performance of CT, MRI or EUS is not sufficient to ensure an accurate selection of patients in whom an R0 resection is likely to be achieved [18]. The insufficient performance of imaging studies after chemotherapy is related to the nature of pancreatic cancer, which is composed of extensive and dense fibrous stroma containing varying densities of tumour cells [18]. Chemotherapy may eliminate tumour cells leaving pre-existing fibrotic stroma or may even induce additional fibrosis, which may be mistakenly interpreted on imaging as persistent tumour [18]. PET-CT may add some information in restaging, as a decrease greater than $50 \%$ in standardised uptake value (SUV) was shown to be a predictor of R0 resection after neoadjuvant chemotherapy [47]. Taking into account the limitations of structural imaging modalities in restaging, additional studies evaluating the potential utility of functional and quantitative imaging techniques are desirable, such as PET-MRI [48] and CT texture analysis [49].

The potential value of new technologies, such as EUS elastography and contrast-enhanced EUS, as an adjunct to EUS in the diagnostic workup of pancreatic masses remains controversial [1]. The first multicentre study eval-

Endoscopic Ultrasound In Pancreatic Cancer Staging uating prospectively the accuracy of EUS elastography for evaluation of pancreatic masses in a large cohort was published 11 years ago [50]. Since then, different studies (all based on strain elastography) reported varied sensitivities and specificities for distinguishing benign from malignant pancreatic masses $[51,52]$. Strain elastography (both qualitative or quantitative) evaluates the relative elasticity of tissue within a region of interest and lacks objectivity and reproducibility [52]. A recent meta-analysis has found that EUS elastography has a high pooled sensitivity $(95 \%)$, but a poor pooled specificity $(61 \%)$ in differentiation of benign and malignant pancreatic masses [51]. A newly developed EUS shear-wave elastography technique will probably improve the accuracy and, most importantly, the reproducibility of EUS elastography in the diagnosis of pancreatic cancer [53]. However, the insufficient specificity of elastography in the diagnosis of pancreatic cancer will probably never be satisfactory due to the fact that stiffness of tissues is not directly related to malignancy, but to various mechanical properties of tissues such as collagen fibre density and distribution [51]. Contrast-enhanced EUS has a higher specificity than strain elastography in the diagnosis of malignancy and may be useful in the characterisation of small $(\leq 2 \mathrm{~cm})$ and ill-defined pancreatic masses, when the enhancement patterns are difficult to depict by CT or MRI $[54,55]$. The combination of contrast-enhanced EUS and elastography may increase specificity in the differentiation of malignant from benign pancreatic masses, achieving a pooled specificity of 76\% [51]. However, the added value of these techniques in the characterisation of indeterminate pancreatic masses after EUS-FNB remains to be proven. In the majority of patients, both EUS elastography and contrast-enhanced EUS add limited value to EUS in the workup algorithm of pancreatic masses, never precluding FNB $[1,51,52]$.

\section{Conclusions}

Accurate staging of pancreatic cancer is challenging due to its morphological variability and to the aggressive biological behaviour of this tumour, frequently associated with extra-pancreatic perineural invasion and dissemination to lymph nodes and distant sites, which may be occult or difficult to detect by cross-sectional imaging studies $[15,18]$. The focus of the initial workup should be to determine the presence of an overt or potentially occult systemic disease on imaging, the likelihood of a complete local resection, and the patient capacity to tol-

GE Port J Gastroenterol 2021;28:111-120 117 


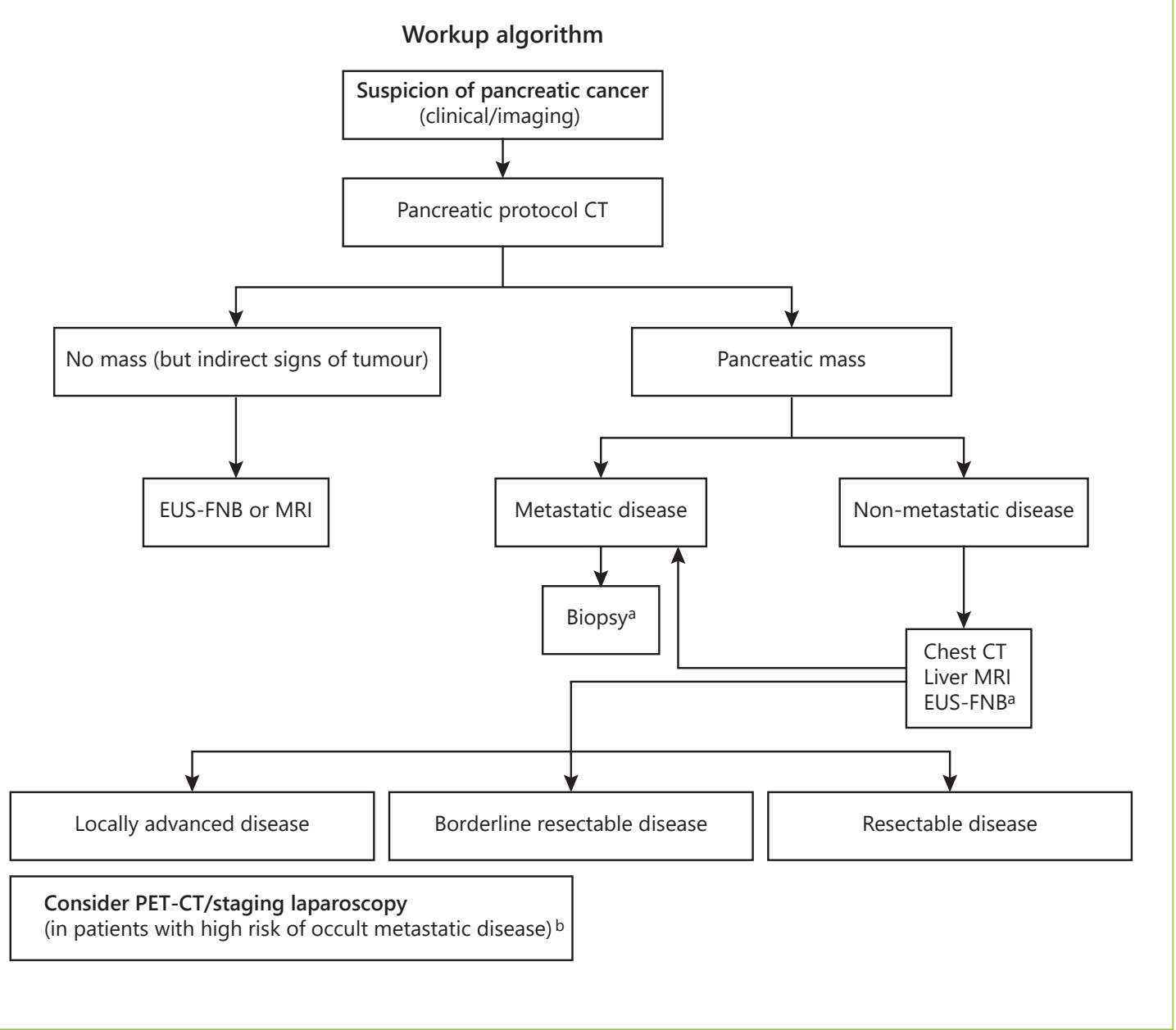

Fig. 3. Multimodality imaging algorithm for pancreatic cancer staging $[4,15,18,19,24,38,39,41,42]$. Key Points: Multi-detector CT, with a dedicated pancreatic protocol, is the first-line tool for diagnosis and tumour staging. No other imaging study is required in metastatic pancreatic cancer, and a biopsy is mandatory before chemotherapy (EUS-guided FNB or image-guided percutaneous biopsy of liver metastases if easily accessible) $[4,15$, $19,24,38,39]$. In non-metastatic pancreatic cancer after initial CT assessment, both MRI and EUS can potentially add information to the staging workup (and a chest CT may also be considered to complete staging). MRI may detect liver metastases in $10 \%$ of patients whose pancreatic cancer is deemed resectable based on CT findings [40]. The potential incremental benefit of EUS for staging is mostly due to the identification of portal vein/ confluence involvement (being particularly valuable in small and ill-defined/isoattenuating tumours), identification of loco-re-

erate available therapies [15]. Each imaging technique has its own diagnostic yield and limitations. A multimodality imaging workup should be pursued as it improves staging accuracy, directing patients with resectable disease to surgery, optimising patient selection to neoadju- gional nodal involvement and documentation of ascites, eventually justifying a diagnostic staging laparoscopy. EUS also allows FNB for histology and assessment of tumour markers and tumour gene profiling $[4,5,9-11,32]$. ${ }^{a}$ A core biopsy is recommended to obtain adequate tissue for possible ancillary studies (immunohistochemistry and molecular profiling). Tumour gene profiling is recommended for patients with locally advanced/ metastatic disease who are candidates for anti-cancer therapy [4]. b PET-CT scan and staging laparoscopy may be considered in high-risk patients to detect extra-pancreatic metastases - particularly in borderline resectable and locally advanced disease, but also in potentially resectable disease $[4,24]$. High-risk features include large primary tumours $(>4 \mathrm{~cm})$, suspicious regional lymph nodes, very highly elevated CA $19.9(>1,000 \mathrm{IU} / \mathrm{mL})$, excessive weight loss and extreme pain $[4,24]$.

vant therapy and avoiding surgical resection in those with more advanced disease [18]. In Figure 3, the authors propose an evidence-based multimodality imaging algorithm for pancreatic cancer staging $[4,15,18,19,24,38$, $39,41,42]$. EUS has become a powerful tool in pancre- 
atic cancer management and should be used as an adjunct modality for staging, potentially changing patient management in non-metastatic disease after the initial cross-sectional imaging assessment $[1,41,42]$. Additionally, it is the method of choice for tumoural sampling [4, $15,24]$, which is playing a pivotal role with neoadjuvant therapy becoming the standard of care in most cases and with the emergence of personalised therapy based on tumour molecular characteristics $[4,6,29]$. The new generation of FNB needles provides true histological samples in $95 \%$ of cases with only two dedicated passes, allowing tumour ancillary testing and molecular profiling $[9-11,35]$.

\section{Conflict of Interest Statement}

All authors disclosed no personal conflicts of interest or financial relationships relevant to this publication.

\section{Funding Sources}

None to report.

\section{Author Contributions}

Miguel Bispo: article concept and design, literature review and draft of the manuscript.

Susana Marques, Ricardo Rio Tinto, Paulo Fidalgo and Jacques Devière: literature review and critical review of the manuscript.

\section{References}

1 Zhang L, Sanagapalli S, Stoita A. Challenges in diagnosis of pancreatic cancer. World $\mathrm{J}$ Gastroenterol. 2018 May;24(19):2047-60.

2 Shrikhande SV, Barreto SG, Goel M, Arya S. Multimodality imaging of pancreatic ductal adenocarcinoma: a review of the literature. HPB (Oxford). 2012 Oct; 14(10):658-68.

3 Wang W, Shpaner A, Krishna SG, Ross WA, Bhutani MS, Tamm EP, et al. Use of EUSFNA in diagnosing pancreatic neoplasm without a definitive mass on CT. Gastrointest Endosc. 2013 Jul;78(1):73-80.

4 National Comprehensive Cancer Network. Pancreatic Adenocarcinoma, Version 1.2020 [accessed 2020 Feb 29]. Available from: https://www.nccn.org/professionals/physician_gls/pdf/pancreatic.pdf.

5 Tempero MA. NCCN Guidelines Updates: Pancreatic Cancer. J Natl Compr Canc Netw. 2019; 17(5.5):603-605.

6 Janssen QP, Buettner S, Suker M, Beumer BR, Addeo P, Bachellier P, et al. Neoadjuvant FOLFIRINOX in patients with borderline resectable pancreatic cancer: a systematic review and patient-level meta-analysis. J Natl Cancer Inst. 2019 Aug;111(8):782-94.

7 Versteijne E, Suker M, Groothuis K, Akkermans-Vogelaar JM, Besselink MG, Bonsing $\mathrm{BA}$, et al. Preoperative chemoradiotherapy vs immediate surgery for resectable and borderline resectable pancreatic cancer: results of the Dutch randomized phase III PREOPANC Trial. J Clin Oncol. 2020 Jun;38(16):1763-1773.

8 Jang JY, Han Y, Lee H, Kim SW, Kwon W, Lee KH, et al. Oncological benefits of neoadjuvant chemoradiation with gemcitabine versus upfront surgery in patients with borderline resectable pancreatic cancer: a prospective, randomized, open-label, multicenter phase 2/3 trial. Ann Surg. 2018 Aug;268(2): $215-22$.

9 Bang JY, Kirtane S, Krall K, Navaneethan U, Hasan M, Hawes R, et al. In memoriam: Fine- needle aspiration, birth: Fine-needle biopsy: The changing trend in endoscopic ultrasound-guided tissue acquisition. Dig Endosc. 2019 Mar;31(2):197-202.

10 Bang JY, Hebert-Magee S, Navaneethan U, Hasan MK, Hawes R, Varadarajulu S. Randomized trial comparing the Franseen and Fork-tip needles for EUS-guided fine-needle biopsy sampling of solid pancreatic mass lesions. Gastrointest Endosc. 2018 Jun;87(6):1432-8.

11 Facciorusso A, Del Prete V, Buccino VR, Purohit P, Setia P, Muscatiello N. Diagnostic yield of Franseen and Fork-Tip biopsy needles for endoscopic ultrasound-guided tissue acquisition: a meta-analysis. Endosc Int Open. 2019;7(10):E1221-E1230.

12 Amin MB, Edge S, Greene F, Byrd DR, Brookland RK, Washington $\mathrm{MK}$, et al., editors. AJCC Cancer Staging Manual. 8th ed. Berlin: Springer International Publishing; 2017.

13 Al-Hawary MM, Francis IR, Chari ST, Fishman EK, Hough DM, Lu DS, et al. Pancreatic ductal adenocarcinoma radiology reporting template: consensus statement of the Society of Abdominal Radiology and the American Pancreatic Association. Radiology. 2014 Jan;270(1):248-60.

14 Gillen S, Schuster T, Meyer Zum Büschenfelde C, Friess H, Kleeff J. Preoperative/neoadjuvant therapy in pancreatic cancer: a systematic review and meta-analysis of response and resection percentages. PLoS Med. 2010 Apr; 7(4):e1000267.

15 Khorana AA, Mangu PB, Berlin J, Engebretson A, Hong TS, Maitra A, et al. Potentially curable pancreatic cancer: american Society of Clinical Oncology clinical practice guideline. J Clin Oncol. 2016 Jul;34(21):2541-56.

16 Khorana AA, Mangu PB, Berlin J, Engebretson A, Hong TS, Maitra A, et al. Potentially curable pancreatic cancer: american Society of Clinical Oncology clinical practice guideline update. J Clin Oncol. 2017 Jul;35(20): 2324-8.
17 Isaji S, Mizuno S, Windsor JA, Bassi C, Fernández-Del Castillo C, Hackert T, et al. International consensus on definition and criteria of borderline resectable pancreatic ductal adenocarcinoma 2017. Pancreatology. 2018 Jan;18(1):2-11.

18 Zins M, Matos C, Cassinotto C. Pancreatic Adenocarcinoma Staging in the Era of Preoperative Chemotherapy and Radiation Therapy. Radiology. 2018 May;287(2):37490.

19 Ducreux M, Cuhna AS, Caramella C, Hollebecque A, Burtin P, Goéré D, et al.; ESMO Guidelines Committee. Cancer of the pancreas: ESMO Clinical Practice Guidelines for diagnosis, treatment and follow-up. Ann Oncol. 2015 Sep;26 Suppl 5:v56-68.

20 Motoi F, Kosuge T, Ueno H, Yamaue H, Satoi S, Sho M, et al.; Study Group of Preoperative Therapy for Pancreatic Cancer (Prep) and Japanese Study Group of Adjuvant Therapy for Pancreatic cancer (JSAP). Randomized phase II/III trial of neoadjuvant chemotherapy with gemcitabine and S-1 versus upfront surgery for resectable pancreatic cancer (Prep-02/JSAP05). Jpn J Clin Oncol. 2019 Feb;49(2):190-4.

21 Labori KJ, Lassen K, Hoem D, Grønbech JE, Søreide JA, Mortensen K, et al. Neoadjuvant chemotherapy versus surgery first for resectable pancreatic cancer (Norwegian Pancreatic Cancer Trial - 1 (NorPACT-1)) - study protocol for a national multicentre randomized controlled trial. BMC Surg. 2017 Aug;17(1): 94.

22 Schwarz L, Vernerey D, Bachet JB, Tuech JJ, Portales F, Michel P, et al. Resectable pancreatic adenocarcinoma neo-adjuvant FOLF(IRIN)OX-based chemotherapy - a multicenter, non-comparative, randomized, phase II trial (PANACHE01-PRODIGE48 study). BMC Cancer. 2018 Jul; 18(1):762. 
23 Janssen QP, Besselink MG, Wilmink JW, van Tienhoven G, Homs M, Groot Koerkamp B; Dutch Pancreatic Cancer Group. The (cost) effectiveness of neoadjuvant FOLFIRINOX vs neoadjuvant gemcitabine-based chemoradiotherapy and adjuvant gemcitabine for (borderline) resectable pancreatic cancer: the PREOPANC-2 study. In: 13th IHPBA World Congress. Geneva, September 7, 2018.

24 Kulkarni NM, Soloff EV, Tolat PP, Sangster GP, Fleming JB, Brook OR, et al. White paper on pancreatic ductal adenocarcinoma from society of abdominal radiology's disease-focused panel for pancreatic ductal adenocarcinoma: part I, AJCC staging system, NCCN guidelines, and borderline resectable disease. Abdom Radiol (NY). 2020;45(3): 716-28.

25 Ryan D, Mamom H. Treatment for potentially resectable exocrine pancreatic cancer. In: Savarese D, editors. UpToDate. [retrieved 2020 Feb 14]. Available from: https://www. uptodate.com/contents/treatment-for-potentially-resectable-exocrine-pancreatic-cancer/print

26 Gerritsen A, Molenaar IQ, Bollen TL, Nio CY, Dijkgraaf MG, van Santvoort HC, et al.; Dutch Pancreatic Cancer Group. Preoperative characteristics of patients with presumed pancreatic cancer but ultimately benign disease: a multicenter series of 344 pancreatoduodenectomies. Ann Surg Oncol. 2014 Nov; 21(12):3999-4006.

27 Waddell N, Pajic M, Patch AM, Chang DK, Kassahn KS, Bailey P, et al.; Australian Pancreatic Cancer Genome Initiative. Whole genomes redefine the mutational landscape of pancreatic cancer. Nature. 2015 Feb; 518(7540):495-501.

28 Aguirre AJ. Refining classification of pancreatic cancer subtypes to improve clinical care. Gastroenterology. 2018 Dec;155(6):1689-91.

29 Puleo F, Nicolle R, Blum Y, Cros J, Marisa L, Demetter $P$, et al. Stratification of pancreatic ductal adenocarcinomas based on tumor and microenvironment features. Gastroenterology. 2018 Dec;155(6):1999-2013.e3.

30 Collisson EA. Bringing pancreas cancer into the lab. Cancer Discov. 2018 Sep;8(9):1062-3.

31 Singhi AD, George B, Greenbowe JR, Chung J, Suh J, Maitra A, et al. Real-time targeted genome profile analysis of pancreatic ductal adenocarcinomas identifies genetic alterations that might be targeted with existing drugs or used as biomarkers. Gastroenterology. 2019 Jun;156(8):2242-2253.e4.

32 Elhanafi S, Mahmud N, Vergara N, Kochman ML, Das KK, Ginsberg GG, et al. Comparison of endoscopic ultrasound tissue acquisition methods for genomic analysis of pancreatic cancer. J Gastroenterol Hepatol. 2019 May; 34(5):907-13.
33 Aguirre AJ, Nowak JA, Camarda ND, Moffitt RA, Ghazani AA, Hazar-Rethinam M, et al Real-time genomic characterization of advanced pancreatic cancer to enable precision medicine. Cancer Discov. 2018 Sep; 8(9): 1096-111.

34 Aung KL, Fischer SE, Denroche RE, Jang GH, Dodd A, Creighton S, et al. Genomics-driven precision medicine for advanced pancreatic cancer: early results from the COMPASS trial. Clin Cancer Res. 2018 Mar;24(6):1344-54.

35 Bang JY, Hebert-Magee S, Navaneethan U, Hasan MK, Hawes R, Varadarajulu S. EUSguided fine needle biopsy of pancreatic masses can yield true histology. Gut. 2018 Dec; 67(12):2081-4.

36 Tiriac H, Belleau P, Engle DD, Plenker D, Deschênes A, Somerville TD, et al. Organoid profiling identifies common responders to chemotherapy in pancreatic cancer. Cancer Discov. 2018 Sep;8(9):1112-29.

37 Lacomb JF, Plenker D, Tiriac H, Bucobo JC, D'souza LS, Khokhar AS, et al. Single-Pass vs 2-Pass Endoscopic Ultrasound-Guided FineNeedle Biopsy Sample Collection for Creation of Pancreatic Adenocarcinoma Organoids. Clin Gastroenterol Hepatol. 2020; 29:S1542-3565(20)30264-0.

38 O'Reilly D, Fou L, Hasler E, Hawkins J, O'Connell S, Pelone F, et al. Diagnosis and management of pancreatic cancer in adults: A summary of guidelines from the UK National Institute for Health and Care Excellence. Pancreatology. 2018 Dec;18(8):962-70.

39 Qayyum A, Tamm EP, Kamel IR, Allen PJ, Arif-Tiwari H, Chernyak V, et al.; Expert Panel on Gastrointestinal Imaging. ACR Appropriateness Criteria ${ }^{\circledR}$ Staging of Pancreatic Ductal Adenocarcinoma. J Am Coll Radiol. 2017 Nov; 14(11 11S):S560-9.

40 Marion-Audibert AM, Vullierme MP, Ronot M, Mabrut JY, Sauvanet A, Zins M, et al. Routine MRI with DWI sequences to detect liver metastases in patients with potentially resectable pancreatic ductal carcinoma and normal liver CT: a prospective multicenter study. AJR Am J Roentgenol. 2018 Nov;211(5):W21725.

41 Nawaz H, Fan CY, Kloke J, Khalid A, McGrath K, Landsittel D, et al. Performance characteristics of endoscopic ultrasound in the staging of pancreatic cancer: a meta-analysis. JOP. 2013 Sep;14(5):484-97.

42 James PD, Meng ZW, Zhang M, Belletrutti PJ, Mohamed R, Ghali W, et al. The incremental benefit of EUS for identifying unresectable disease among adults with pancreatic adenocarcinoma: A meta-analysis. PLoS One. 2017 Mar;12(3):e0173687.

43 Gonçalves B, Soares JB, Bastos P. Endoscopic Ultrasound in the Diagnosis and Staging of Pancreatic Cancer. GE Port J Gastroenterol. 2015 Jul;22(4):161-71.
44 Mansfield SD, Scott J, Oppong K, Richardson DL, Sen G, Jaques BC, et al. Comparison of multislice computed tomography and endoscopic ultrasonography with operative and histological findings in suspected pancreatic and periampullary malignancy. Br J Surg. 2008 Dec;95(12):1512-20.

45 Kala Z, Válek V, Hlavsa J, Hana K, Vánová A. The role of $\mathrm{CT}$ and endoscopic ultrasound in pre-operative staging of pancreatic cancer. Eur J Radiol. 2007 May;62(2):166-9.

46 Li D, Hu B, Zhou Y, Wan T, Si X. Impact of tumor size on survival of patients with resected pancreatic ductal adenocarcinoma: a systematic review and meta-analysis. BMC Cancer. 2018 Oct;18(1):985.

47 Choi M, Heilbrun LK, Venkatramanamoorthy R, Lawhorn-Crews JM, Zalupski MM, Shields AF. Using 18F-fluorodeoxyglucose positron emission tomography to monitor clinical outcomes in patients treated with neoadjuvant chemo-radiotherapy for locally advanced pancreatic cancer. Am J Clin Oncol. 2010 Jun;33(3):257-61.

48 Joo I, Lee JM, Lee DH, Lee ES, Paeng JC, Lee SJ, et al. Preoperative assessment of pancreatic cancer with FDG PET/MR imaging versus FDG PET/CT plus contrast-enhanced multidetector CT: a prospective preliminary study. Radiology. 2017 Jan;282(1):149-59.

49 Cassinotto C, Chong J, Zogopoulos G, Reinhold C, Chiche L, Lafourcade JP, et al. Resectable pancreatic adenocarcinoma: role of CT quantitative imaging biomarkers for predicting pathology and patient outcomes. Eur J Radiol. 2017 May;90:152-8.

50 Giovannini M, Thomas B, Erwan B, Christian P, Fabrice C, Benjamin E, et al. Endoscopic ultrasound elastography for evaluation of lymph nodes and pancreatic masses: a multicenter study. World J Gastroenterol. 2009 Apr;15(13):1587-93.

51 Zhang B, Zhu F, Li P, Yu S, Zhao Y, Li M. Endoscopic ultrasound elastography in the diagnosis of pancreatic masses: A meta-analysis. Pancreatology. 2018 Oct;18(7):833-40.

52 Chantarojanasiri T, Kongkam P. Endoscopic ultrasound elastography for solid pancreatic lesions. World J Gastrointest Endosc. 2017 Oct;9(10):506-13.

53 Ohno E, Hirooka Y, Kawashima H, Ishikawa T. Feasibility of EUS-guided shear-wave measurement: A preliminary clinical study. Endosc Ultrasound. 2019 May-Jun;8(3):215-6.

54 Kitano M, Kudo M, Yamao K, Takagi T, Sakamoto $\mathrm{H}$, Komaki T, et al. Characterization of small solid tumors in the pancreas: the value of contrast-enhanced harmonic endoscopic ultrasonography. Am J Gastroenterol. 2012 Feb;107(2):303-10.

55 Yamashita Y, Shimokawa T, Napoléon B, Fusaroli P, Gincul R, Kudo M, et al. Value of contrast-enhanced harmonic endoscopic ultrasonography with enhancement pattern for diagnosis of pancreatic cancer: A meta-analysis. Dig Endosc. 2019 Mar;31(2):125-33. 